\title{
ANÁLISE AMBIENTAL E PROCESSO DE DESERTIFICAÇÃO NO SEMIÁRIDO DA BAHIA: DISSECÇÃO DOS PERFIS SOCIODEMOGRÁFICOS DOS MUNICÍPIOS SUSCETÍVEIS À DESERTIFICAÇÃO NOS PÓLOS DE IRECÊ E GUANAMBI
}

\author{
João Victor Trindade Melo Guerra ${ }^{\mathbf{1}}$; Nacelice Barbosa Freitas ${ }^{2}$; \\ 1. Bolsista PEVIC/FAPESB, Graduando em licenciatura em Geografia, Universidade e Estadual de Feira de Santana, e-mail: \\ jguerrafsa@gmail.com \\ 2. Orientador, Departamento de Ciências Humanas e Filosofia, Universidade Estadual de Feira de Santana, e-mail: \\ nacegeografic@hotmail.com
}

PALAVRAS-CHAVE: Degradação; Vulnerabilidade; Semiárido Brasileiro;

\section{INTRODUÇÃO}

A desertificação é um problema bastante discutido e tem chamado atenção da comunidade acadêmica, assim como de toda a sociedade, em virtude dos problemas socioambientais mundiais na atualidade. Nas convenções climáticas o tema é sempre abordado e a Convenção das Nações Unidas para o Combate à Desertificação e Mitigação dos Efeitos das Secas (UNCCD), identificou 193 países, incluindo o Brasil, como espaços susceptíveis à desertificação. Para a Organização das Nações Unidas (ONU) a definição desse processo resulta de vários fatores, tanto naturais como sociais, levando a degradação nas áreas semiáridas, subsumidas secas e áridas.

No Brasil, especialmente na Região Nordeste encontram-se os espaços mais suscetíveis à desertificação, principalmente quando se trata da região semiárida. $\mathrm{Na}$ Bahia aproximadamente $70 \%$ da extensão territorial situa-se nesta sub-região, podendo-se identificar várias áreas que apresentam tal vulnerabilidade. Entre estas, identificam-se os municípios que integram os Pólos de Guanambi, Irecê, Juazeiro e Jeremoabo, localizados no Norte e Nordeste do Estado, e conforme Vale (2009) se enquadram no Semiárido, com localização controlada pela Depressão Sertaneja, formado sobre o embasamento cristalino, sendo caracterizado pelo déficit hídrico, com irregularidade de chuvas, e predominância de solos rasos, pedregosos, lajedos e paredões.

Os Pólos de Guanambi e Irecê foram escolhidos para a realização da pesquisa, especialmente por apresentar significativa degradação ambiental, estando em situação de vulnerabilidade socioambiental, relacionada às condições da natureza. Nesse sentido, refletir sobre os problemas socioambientais afirmando que estes podem ser minimizados através da implementação de políticas públicas específicas que atendam aos municípios propensos à desertificação.

Este resumo tem por objetivo identificar os dados sociodemográficos, especificamente os indicadores sociais de desenvolvimento entre 2000 e 2010, dos municípios dos Pólos de Guanambi e Irecê para relacionar a evolução dos mesmos aos processos de degradação ambiental e desertificação. Dessa forma, a vulnerabilidade socioambiental nos espaços definidos para análise, assinalam para a necessidade da implementação de políticas públicas que tenham por meta o desenvolvimento territorial, e a realização de estudos que visem novas produções científicas sobre os dados sociodemográficos, referentes Áreas Suscetíveis à Desertificação (ASD).

\section{MATERIAS E MÉTODOS}


Os dois Pólos estão localizados no domínio morfoclimático do semiárido brasileiro, conforme afirma Ab'Saber (2003), área que corresponde a 30\% da região Nordeste, possuindo uma estrutura agrária concentradora que acentua a pobreza e possibilita a miséria decorrente dos períodos de secas. O semiárido apresenta em destaque o clima que é responsável por outros aspectos que compõem a paisagem, desse modo destacam-se as alterações em relação à vegetação e ao processo de formação do relevo (ARAÚJO, 2011).

Para a produção da pesquisa foi realizada uma revisão bibliográfica dando suporte teórico e conceitual necessário à explicação do tema, como também o levantamento de dados sociodemográficos: Índice de Desenvolvimento Humano Municipal (IDHM), Índice de Desenvolvimento Social (IDS) e o Índice de Desenvolvimento Educacional, com objetivo de analisar os indicadores sociais, e explicar a situação socioambiental interligada ao processo de desertificação dos municípios que integram os Pólos de Guanambi e Irecê.

\section{RESULTADO E DISCUSSÃO}

A degradação ambiental nos Pólos de Irecê e Guanambi mostra a importância de estudar o processo de desertificação nos 30 municípios que formam os dois Pólos. Durante muito tempo à desertificação nos municípios foram explicados como um processo meramente climático e natural, Para Nimer (1988), esse pensamento da desertificação será uma das vicissitudes do clima, pois entendia desertificação como algo natural, de maneira que seria impossível de evitar. Com a evolução dos estudos sobre as ASD, vemos que o mesmo pouco tem a ver com o natural, mas uma maior parte relacionada às ações humanas, como: o uso indevido do solo, a criação extensiva de gado, queimadas que tiram toda cobertura vegetal e a eliminação de agentes polinizadores.

O Pólo de Guanambi, formado por 14 municípios, mostrou em 2000 que apenas o município de Caetité tinha o IDHM maior que 0,600. Nos municípios restantes Gunambi tinha o IDHM considerado baixo e os 12 restantes eram de valores muito baixo, sendo Lagoa Real o pior entre eles com apenas 0,360. Já em 2010 os valores do IDHM aumentaram, porém apenas sete municípios estão com números maiores que 0,600. Guanambi passou a ser o com melhor IDHM 0,673, e Lagoa Real continua com o menor índice 0,545.

Durante o período de 2000, 2002, 2004 e 2006 vemos que os indicadores sociais dos municípios estão cada vez menores, sendo assim, os problemas de Políticas Públicas e administração pública dificultam o desenvolvimento dos 14 municípios do Pólo de Guanambi, que sem projetos que busquem solucionar à degradação ambiental e à desertificação, fazem com que problemas sociodemográficos aumentem cada vez mais.

\begin{tabular}{|l|c|c|c|c|}
\hline \multirow{2}{*}{$\begin{array}{c}\text { MUNICÍPIOS DO PÓLO DE } \\
\text { GUANAMBI }\end{array}$} & \multicolumn{3}{|c|}{ VALORES DO IDS } \\
\cline { 2 - 5 } & $\mathbf{2 0 0 0}$ & $\mathbf{2 0 0 2}$ & $\mathbf{2 0 0 4}$ & $\mathbf{2 0 0 6}$ \\
\hline PALMAS DE MONTE ALTO & $4.960,53$ & $4.971,64$ & $4.969,29$ & $4.978,57$ \\
\hline CAETITÉ & $5.039,81$ & $5.064,50$ & $5.037,64$ & $5.008,54$ \\
\hline MATINA & $4.949,07$ & $4.932,22$ & $4.937,14$ & $4.932,90$ \\
\hline IGAPORÃ & $4.952,02$ & $4.974,86$ & $4.976,23$ & $4.980,80$ \\
\hline CANDIBA & $4.988,98$ & $4.994,94$ & $4.997,88$ & $4.992,61$ \\
\hline URANDI & $5.048,69$ & $5.002,79$ & $4.977,17$ & $4.985,14$ \\
\hline LAGOA REAL & $4.902,27$ & $4.920,41$ & $4.922,29$ & $4.924,78$ \\
\hline SEBASTIÃO LARANJEIRAS & $4.987,71$ & $4.990,79$ & $4.985,46$ & $4.974,94$ \\
\hline
\end{tabular}




\begin{tabular}{|l|r|r|r|r|}
\hline IUIÚ & $4.991,92$ & $4.961,97$ & $4.968,67$ & $4.967,10$ \\
\hline PINDAÍ & $4.945,83$ & $4.958,50$ & $4.970,86$ & $4.958,05$ \\
\hline LICÍNIO DE ALMEIDA & $5.002,41$ & $4.998,22$ & $5.007,09$ & $5.010,63$ \\
\hline GUANAMBI & $5.104,10$ & $5.103,72$ & $5.087,24$ & $5.083,88$ \\
\hline MALHADA & $4.975,58$ & $4.982,85$ & $4.959,90$ & $4.971,32$ \\
\hline LIVRAMENTO DE NOSSA SENHORA & $5.026,24$ & $5.011,49$ & $5.010,87$ & $5.007,86$ \\
\hline
\end{tabular}

Fonte: SEI, 2006.

Tabela 1 - valores do ids nos municípios do Pólo de Guanambi

O município de Guanambi tinha em 2000 o melhor IDS entre os demais, porém mesmo continuando com o principal IDS, o seu valor caiu durante os anos seguintes, realçando o problema de Políticas Públicas no Pólo.

O Pólo de Irecê é composto por 16 municípios, todos se localizam na ADS. Os dados dos municípios mostram que em 2000 Irecê tinha o valor de IDHM mais alto com 0,542, sendo que, é um valor considerado baixo, os outros 15 municípios tinham valores alarmantes que no IDHM são considerados muito baixos. Em 2010, assim como o Pólo de Guanambi, ocorreu um aumento no IDHM, porém muitos municípios ainda estão com valores baixos. Irecê continua sendo a cidade com maior IDHM do Pólo 0,691. Esses dados demonstram uma situação preocupante, na qual apenas Irecê teve um crescimento considerável.

O IDS do Pólo de Irecê mostra que ocorreu uma queda nos valores dos seus indicadores durante 2000, 2002, 2004 e 2006, principalmente de 2000 para 2002, que mesmo tendo um crescimento nos anos seguintes, o valor ainda está abaixo do esperado. A falta de políticas públicas foi, e ainda é, um grande problema para quem vive nessas áreas, para que projetos sejam realizados com a real intenção de desenvolver os municípios suscetíveis à desertificação é importante que haja estudos que busquem soluções individuais por área estudada, e não uma solução que seja utilizada de maneira única por todos, como foi proposto por Sales (2013).

\begin{tabular}{|c|c|c|c|c|}
\hline \multirow[b]{2}{*}{ MUNICÍPIOS DO PÓLO DE IRECÊ } & \multicolumn{4}{|c|}{ VALORES DO IDS } \\
\hline & 2000 & 2002 & 2004 & 2006 \\
\hline SÃO GABRIEL & $4.973,43$ & $4.964,61$ & $4.970,69$ & $4.959,62$ \\
\hline JUSSARA & $4.984,10$ & $4.974,68$ & $4.972,71$ & $4.979,26$ \\
\hline CENTRAL & $5.028,26$ & $5.042,70$ & $5.014,51$ & $4.996,15$ \\
\hline UIBAÍ & $4.974,18$ & $5.017,20$ & $4.981,69$ & $5.000,33$ \\
\hline IBITITÁ & $5.000,62$ & $5.004,20$ & $5.006,49$ & $4.992,70$ \\
\hline JOÃO DOURADO & $5.030,38$ & $5.033,15$ & $5.028,65$ & $5.038,05$ \\
\hline IBIPEBA & $5.008,10$ & $5.049,12$ & $5.034,32$ & $5.024,78$ \\
\hline BARRA DO MENDES & $5.045,25$ & $4.928,33$ & $4.999,89$ & $5.020,98$ \\
\hline BARRO ALTO & $4.985,73$ & $4.987,90$ & $4.983,42$ & $4.983,65$ \\
\hline CANARANA & $4.997,41$ & $4.989,64$ & $4.996,61$ & $4.987,29$ \\
\hline CAFARNAUM & $4.988,28$ & $4.976,24$ & $4.977,91$ & $4.972,79$ \\
\hline ITAGUAÇU DA BAHIA & $4.950,74$ & $4.944,74$ & $5.062,13$ & $5.062,13$ \\
\hline LAPÃO & $4.979,28$ & $4.979,29$ & $4.985,26$ & $4.984,58$ \\
\hline PRESIDENTE DUTRA & $5.010,33$ & $5.022,58$ & $5.013,48$ & $5.017,34$ \\
\hline AMÉRICA DOURADA & $5.129,68$ & $4.962,46$ & $4.978,07$ & $4.986,36$ \\
\hline
\end{tabular}


Tabela 2 - valores do IDS nos municípios do Pólo de Irecê

\section{CONSIDERAÇÕES FINAIS}

Como foi perceptível, os municípios dos Pólos de Irecê e Guanambi mostram um problema alarmante devido à falta de Políticas Públicas que agravam o processo de degradação e à desertificação que ocorre nos municípios, por conta de estudos que não se preocupam com a individualidade característica de cada Pólo.

Ainda existem muitos discursos que relacionam os problemas demográficos com o clima e o baixo índice pluviométrico, porém a maioria dos municípios dos Pólos mostram problemas na forma como são administrados, sendo assim, o principal motivo dos problemas sociais e econômicos dos municípios são causados pela ação humana e não de maneira natural.

É necessário que haja uma evolução na forma como são estudados os Pólos de Guanambi e Irecê, pois por meio de avanços nos estudos de cada um dos municípios, encontrar-se-ão soluções que se apropriem de características individuais, mostrando os reais motivos dos problemas sociodemográficos ocorridos nas áreas em questão, podendo assim chegar a uma solução viável.

\section{REFERÊNCIAS}

AB'SÁBER, A. Os domínios de natureza no Brasil: potencialidades paisagísticas. São Paulo: Ateliê Editorial, 2003.

ARAÚJO, Sérgio Murilo Santos de. A região semiárida do nordeste do Brasil: Questões Ambientais e Possibilidades de uso Sustentável dos Recursos. Revista Científica da FASETE. n. 5, 2011.

GARCIA, C. O Que É Nordeste Brasileiro. São Paulo: Editora Brasiliense S.A., 1984.

GUERRA, Antônio Teixeira; GUERRA, Antônio José Teixeira. Novo Dicionário GeológicoGeomorfológico. Rio de Janeiro: Bertrand Brasil, 1997.

NIMER, E. Desertificação: realidade ou mito? Revista Brasileira de Geografia, Rio de Janeiro, v. 50, n.1, 1988.

SALES, M. C. L. Evolução dos Estudos de Desertificação no Nordeste Brasileiro. GEOUSP Espaço e Tempo, São Paulo, No 14, 2003.

SILVA, Roberto Marinho Alves da. Entre o Combate à Seca e a Convivência com o Semiárido: Políticas públicas e transição pragmática. Revista Econômica do Nordeste, Fortaleza, v. 38, n 3, jul-set. 2007.

SILVA, Sylvio C. Bandeira de M. \&amp; FONSECA, Antonio Angelo M. IX Coloquio Internacional de Geocrítica. Políticas Territoriais de Integração e Fortalecimento dos Centros Urbanos do Estado da Bahia/Brasil. Porto Alegre, 2007.

VALE, Raquel de Matos Cardoso. Degradação ambiental e processos de desertificação no estado da Bahia. Universidade Estadual de Feira de Santana, 2009.

AB'SÁBER, A. Os domínios de natureza no Brasil: potencialidades paisagísticas. São Paulo: Ateliê Editorial, 2003. 